\title{
Research on friction stir welded joints of Copper to Magnesium alloy Yuhua $\mathrm{CHEN}^{1, a^{*}}$, Jilin $\mathrm{XIE}^{1, \mathrm{~b}}$ and Wenming $\mathrm{CAO}^{1, \mathrm{c}}$ \\ ${ }^{1}$ School of Aerospace Manufacturing Engineering, Nanchang Hangkong University, P. R. China \\ ach.yu.hu@163.com, b294235585@qq.com, Cao_wenming2011@163.com
}

\section{Keywords: Mg/Cu dissimilar joint, FSW, Microstructure, Mechanical properties}

\begin{abstract}
Dissimilar magnesium alloy AZ31 and pure copper sheets with a thickness of 5mm were successfully friction stir welded. Microstructure and mechanical properties of the butt joints were investigated. Complicated microstructure was formed in the nugget zone, in which vortex-like pattern and lamella structure could be found. $\mathrm{CuMg}_{2}$ intermetallic compounds were found in the nugget zone. The hardness of the stir zone was much higher than that of the base material. The maximum value of hardness existing in the middle of the stir zone. Hardness values near the $\mathrm{Mg}$ side were relatively higher than that of near the $\mathrm{Cu}$ side in the weld zone. The ultimate tensile strength (UTS) of the joint was $86 \mathrm{MPa}$ and the joint failed with a brittle fracture mode.
\end{abstract}

\section{Introduction}

Aiming to reduce the vehicle weight and in turn cut down fuel consumption, magenisum alloys, the lightest structure metallic material with high specific strength and high specific stiffness, are widely used in the atuomotive and aerospace industries in recent years. They also have attractive electromagnetic and thermal conductive properties and therefor have been increasingly used in the electronic industry $[1,2]$. Copper and its alloys also have a wide application in electronic and electrical power industry, electrical appliances and automobiles [3]. It has been reported that $\mathrm{Cu}-\mathrm{Mg}$ bimetals are widely used in the electronic and electrical industries, electrical appliances, machinery and automobile industries [4]. Welding processing is essential to make the $\mathrm{Cu}-\mathrm{Mg}$ bimetals. However, the joining of $\mathrm{Cu}$-to- $\mathrm{Mg}$ alloy through conventional fusion welding processes remains a major challenge due to the huge difference in the melting point, formation of intermetallic compounds (IMCs), and severe thermal cracking. Liming Liu investigated the TIG welding of $\mathrm{Mg}$ to $\mathrm{Cu}$ [5], he found that metallic oxide and intermetallic compounds are the main reason that weak the joints strength. Moreover, Caiwang Tan joined these two metals by fiber laser-TIG hybrid welding [6], the different morphologies including $\mathrm{Mg}-\mathrm{Cu}$ eutectic structure, $\mathrm{Mg}-\mathrm{Cu}$ intermetallic compound and $\mathrm{Mg}$-Al-Cu ternary intermetallic compound were identied at the $\mathrm{Mg}-\mathrm{Cu}$ interface. $\mathrm{R}$. Cao obtained $\mathrm{Mg}-\mathrm{Cu}$ welding-brazing joint via cold metal transfer welding processing by using $\mathrm{AZ}_{61} \mathrm{~A}$ magensium alloy wire as filler metal [7], the interfacial reaction layers of the brazing joint consisted of $\mathrm{Mg}_{2} \mathrm{Cu}, \mathrm{Al}_{6} \mathrm{Cu}_{4} \mathrm{Mg}_{5}, \mathrm{MgCu}_{2}$ and $\mathrm{Mg}_{17} \mathrm{Al}_{12}$ IMCs.

As a result, alternative solid-state joining techniques like friction stir welding (FSW), ultrasonic spot welding (USW), and diffusion bonding are of special interest due to their potential of obtaining superior joint properties compared with the fusion welding techniques. G. Mahendran studied diffusion bonding of AZ31B magnesium and copper alloys [8], they found that The principal difficulty when joining $\mathrm{Mg}-\mathrm{Cu}$ lies in the existence of hard-to-remove oxide films on the magnesium surfaces and the formation of brittle metallic interlayers and oxide inclusions in the bond region, the optium lap shear test strength of the joint is $66 \mathrm{MPa}$.

Many researchers have concluded that friction stir welding can over come the problems that occur during fusion welding process [9], while the joining of $\mathrm{Mg}$ to $\mathrm{Cu}$ by FSW was not reported until nowadays. In the present study, the AZ31 magnesium alloy and pure copper are butt welded via FSW. After welding, the weld surface and cross-section appearances were investigated. Further, the microstructure, interfacial structure and mechanical properties of the joints were researched. 


\section{Experimental Details}

AZ31B and pure copper plates with dimensions of $300 \mathrm{~mm} \times 110 \mathrm{~mm} \times 5 \mathrm{~mm}$ were used in the present study. The chemical compositions and mechanical properties of the two materials are shown in Table 1. Friction stir butt welding of magnesium alloy with pure copper was conducted by offsetting probe edge into the pure copper, as illustrated by Fig. 1. The pure copper was positioned on the advancing side and the aluminum alloy was on the retreating side. The welding tool of FSW was made of a nickle based superalloy and consisted of a concave shoulder of $24 \mathrm{~mm}$ diameter and a cylinder probe of $4.7 \mathrm{~mm}$ length and $6 \mathrm{~mm}$ diameter. The probe offset distance was selected to be $0.5 \mathrm{~mm}$ in the present study. Therefore, the stirring action of the probe mainly happened in the magnesium alloy part of the joint. Dissimilar friction stir welding was carried out at a tool rotation rate of $1180 \mathrm{r} / \mathrm{min}$ and a traverse speed of $38 \mathrm{~mm} / \mathrm{min}$ with the butt joint parallel to the rolling direction of the sheets. Before welding, the joint surface of pure copper and magnesium alloys was machined by a milling machine and degreased with acetone.

Table 1. Chemical compositions and mechanical properties of the base materials (wt.\%).

\begin{tabular}{cccccccc}
\hline Materials & $\mathrm{Mg}$ & $\mathrm{Al}$ & $\mathrm{Zn}$ & $\mathrm{Mn}$ & $\mathrm{Cu}$ & $\begin{array}{c}\text { Tensile strength } \\
\sigma_{\mathrm{b}}(\mathrm{Mpa})\end{array}$ & $\begin{array}{c}\text { Elongation } \\
(\%)\end{array}$ \\
\hline AZ31B & Bal. & 3 & 1 & 0.2 & - & 240 & 14 \\
$\mathrm{Cu}$ & - & - & - & - & Bal. & 250 & 15 \\
\hline
\end{tabular}

After welding, the joints were cross-sectioned perpendicularly to the welding direction for defect examination and metallographic analysis. The microstructures of joints were observed by optical microscope (OM) and scanning electron microscope (SEM) equipped with an energy-dispersive $\mathrm{X}$-ray spectrometer (EDS). The specimens for $\mathrm{OM}$ were etched with different etchants $(50 \mathrm{ml}$ $\mathrm{NH}_{4} \mathrm{OH}+20 \mathrm{ml} \mathrm{H}_{2} \mathrm{O}_{2}+50 \mathrm{ml} \mathrm{H} \mathrm{O}_{2}$ for $\mathrm{Cu}$ side and $4 \mathrm{mlHNO}_{3}+95 \mathrm{mlC}_{2} \mathrm{H}_{5} \mathrm{OH}$ for $\mathrm{Mg}$ side). Tensile specimens were cross-sectioned perpendicular to the welding direction, the dimension of the tensile specimen was shown in Fig. 2 with the surfaces of no machining.

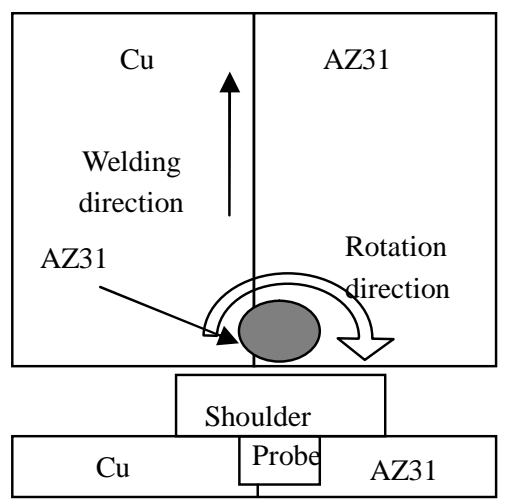

Fig. 1 Set-up of Mg-Cu dissimilar FSW.

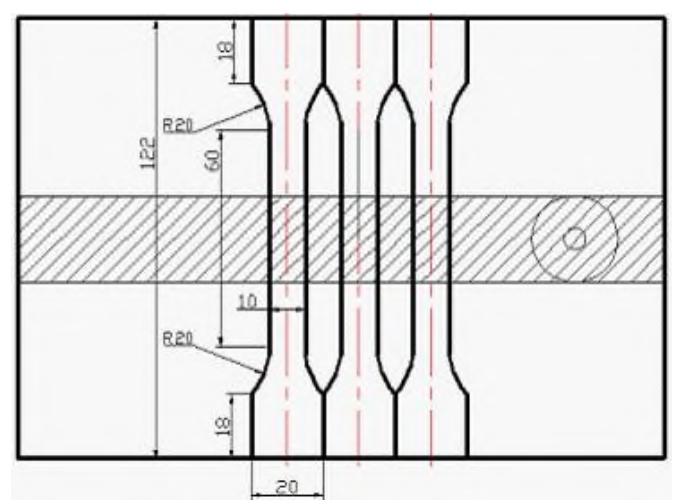

Fig. 2 Size of tensile test samples.

The strength of the joint was evaluated via tensile test at room temperature. The tensile test was carried out using a testing machine WDS-100 at a crosshead speed of $1 \mathrm{~mm} / \mathrm{min}$. Three specimens were tested, and the average value was used to evaluate the tensile strength of the joint. Hardness measurement was performend on the metallographic specimen crossing the joints at the top, middle and bottom line across the weld zone, using a vickers intendenter and a load of $100 \mathrm{gf}$ for a dwelling time of $10 \mathrm{~s}$, and the distance between two neighboring indentations was $500 \mu \mathrm{m}$.

\section{Results and Discussion}

Macrostructure and Microstructure of Dissimilar Joint. Fig. 3 shows the surface morphology of the dissimilar welded seam. The surface of the joint is covered by a layer of magnesium alloy and 
some small flash can be found at the edge of the joint. Fig. 4 shows the cross sectional macrostructure of the dissimilar weld. The nugget zone is composed of magnesium and copper. Onion-like pattern is formed at the bottom of the nugget zone and its structure is complicated due to the dissimilar materials flow. No pore or other defect can be found in Figs. 3 and 4, indicating that sound joint could be produced with the designated experimental parameters.

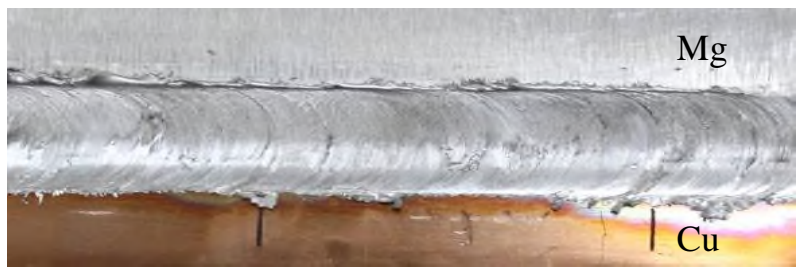

Fig. 3 Surface appearance of the welded joint.

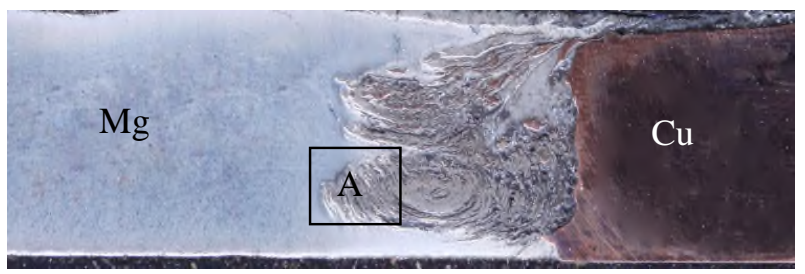

Fig. 4 Cross-section of the welded joint.

Different regions around the cross-section of the FSW joint are shown in Fig. 5.
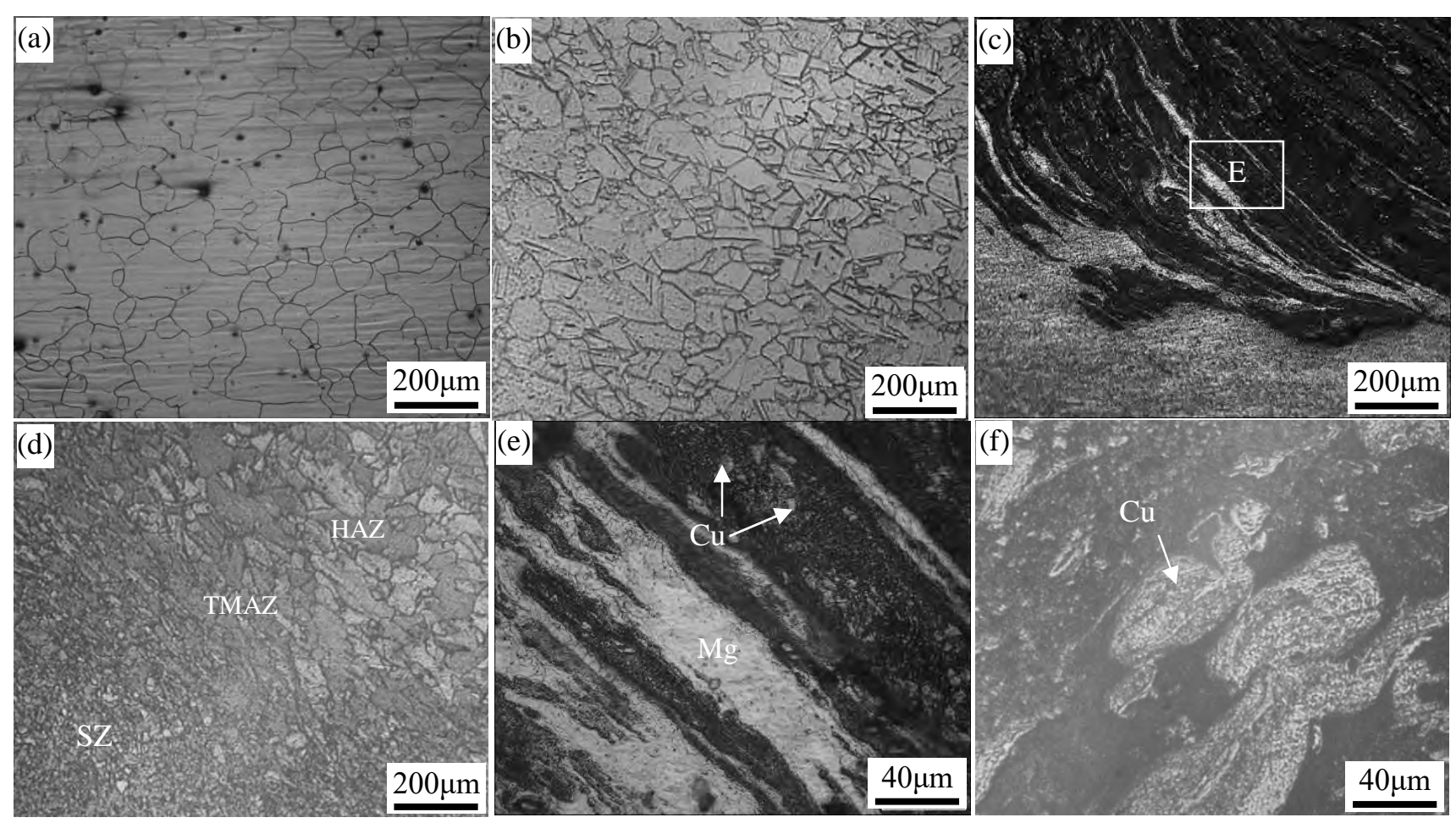

Fig. 5 Microstructure of Cu-AZ31Mg dissimilar joint: (a) Mg base metal, (b) $\mathrm{Cu}$ base metal, (c) region A marked in Fig. 3(b), (d) Cu after welding processing, (e) Magnified microstructure of region $\mathrm{E}$ marked in Fig. 4(c), (f) $\mathrm{Cu}$ fragments at nugget zone.

Fig. 5(a) and (b) show microstructures of the pre-welded base metal of AZ31B, pure copper, respectively. As shown in Fig. 5(a), the microstructure of AZ31 BM is mainly consist grains of unequal sizes and distributions. Fig. 5(b) shows the microstructure of pure copper BM, which is a mixture of coarse and fine copper grains. Fig. 5(c) is the magnified picture of area A in Fig. 4. A lamellae structure composed of copper particles with a streamline shape and continuous magnesium strips can be observed in the Fig.. Further magnified pictures in this area was shown in Fig. 5(e). This interlaced structure formed by magnesium and copper particles indicates that the dissimilar sheets are bonded together firmly in this region. As shown in Fig. 5(f), the copper fragments with an elongated shape indicate that severe plastic deformation has taken place during FSW. Fig. 5(d) shows the microstructures of HAZ and TMAZ in the copper side. No plastic deformation occurred in HAZ, but the grains in HAZ were heated to grow during FSW. The grains in TMAZ show a curved shape, indicating that these grains undergo notable plastic deformation caused by the welding tool. 
Fig. 6 shows the SEM analysis of the dissimilar joint. Fig. 6(a) shows the cross-sectional macrograph of the dissimilar weld. As shown in Fig. 6(a), there is no obvious welding defect in the joint and a complex material flow is observed in the SZ. Since most of the rotating pin is inserted into the magnesium side, the majority of the nugget is AZ31 magnesium alloy, and copper is distributed in this zone with different shapes. In the upper part of the joint, large bulk of copper with irregular shapes can be observed, while in the bottom part of joint copper, continuous strips with elongated shapes exist. Moreover, the intermixing of copper and magnesium is complicated and different microstructures are formed in different regions of the nugget.
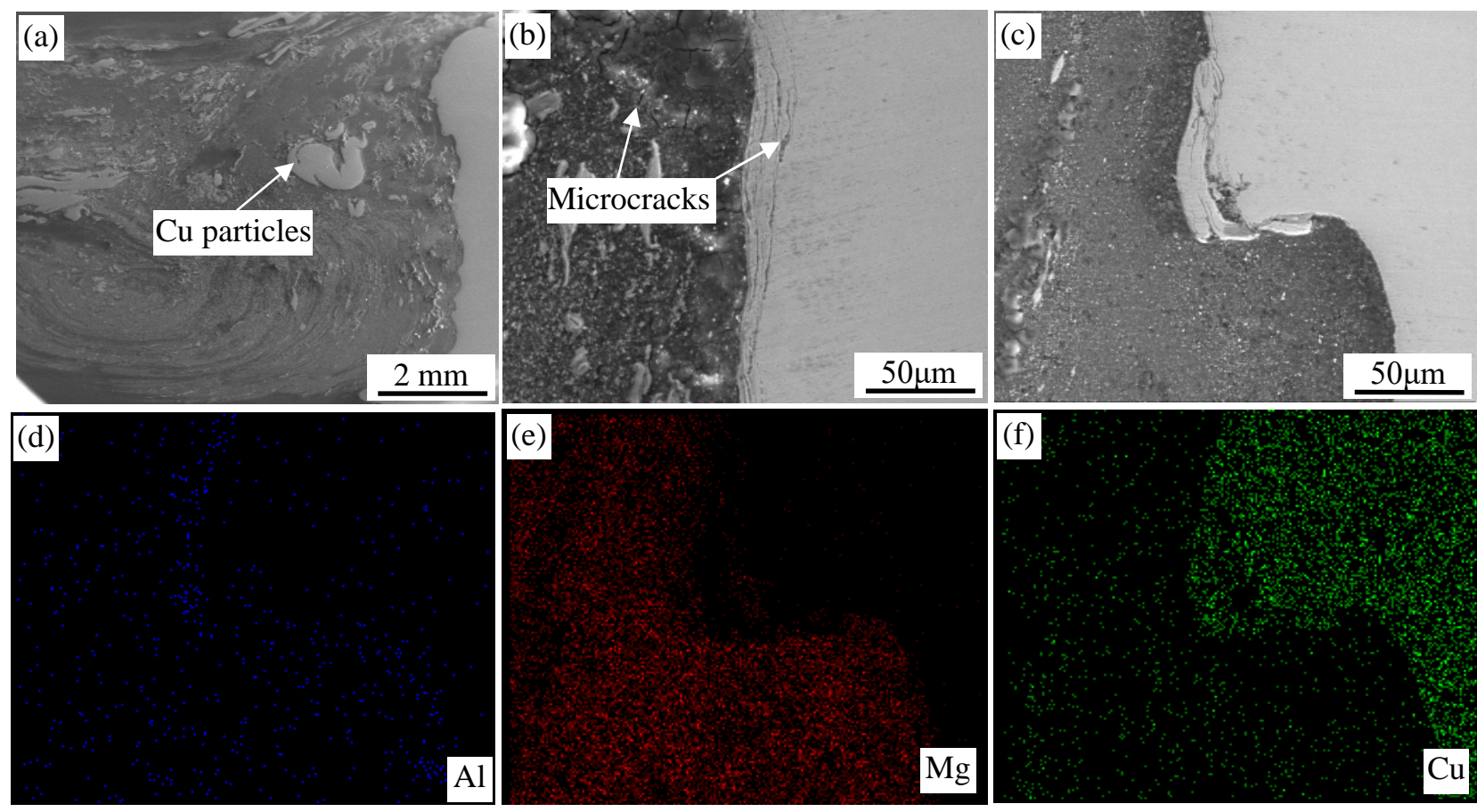

Fig. 6 Interfacial structures and elements distribution images of $\mathrm{Mg}-\mathrm{Cu}$ dissimilar joints.

Fig. 6(b) and (c) show the joints' interfacial microstructure located at the upper part and bottom part, respectively. As shown in Fig. 6(b), micro cracks were observed at the Mg side. And these cracks were not found at the bottom part in Fig. 6(c). The reason may lies in that temperature at the upper part was higher than that at the bottom part. At the $\mathrm{Cu}$ side, micro cracks were observed in both Fig. 6(b) and (c). Combined influence of temperature and plastic deformation induced by the stirring action suggests the formation of the microcracks. Fig. 6(d)-(f) are the EDS map taken from Fig. 6(c). Al element with a color of blue is distributing mostly in Mg side. As shown in Fig. 6(d), $\mathrm{Mg}$ element is only found in $\mathrm{Mg}$ side. The concentration of $\mathrm{Mg}$ elements are decreasing at the $\mathrm{Cu}-\mathrm{Mg}$ boundary indicting chemical reaction between $\mathrm{Cu}$ and $\mathrm{Mg}$ are happened at the interface. Fig. 6(f) is the distribution profile of $\mathrm{Cu}$ element with green color. It can be clearly seen that $\mathrm{Cu}$ element is distributing across the whole map. As mentioned above, $\mathrm{Cu}$ material was stirred into the nugget zone by welding tool during the welding process. Chemical reactions were took place when $\mathrm{Cu}$ fragments contact with $\mathrm{Mg}$ in the nugget zone during the welding process. So $\mathrm{Cu}$ element distributed all over the nugget zone.

Fig. 7 shows the XRD pattern measured at the fracture surface on $\mathrm{Mg}$ side, $\mathrm{CuMg}_{2} \mathrm{IMCs}$ was produced in the dissimilar joint. This is indicated that chemical reactions between $\mathrm{Cu}$ and $\mathrm{Mg}$ were took place during the FSW process. By referring to the $\mathrm{Cu}-\mathrm{Mg}$ binary phase diagram shown in Fig. $8, \mathrm{Mg}_{2} \mathrm{Cu}$ compounds should be produced via a eutectic reaction $\left(\mathrm{L} \rightarrow \mathrm{Mg}+\mathrm{Mg}_{2} \mathrm{Cu}\right.$ ). However, Liu Liming found that both $\mathrm{Mg}_{2} \mathrm{Cu}$ and $\mathrm{MgCu}_{2}$ formed at the nugget zone during $\mathrm{Cu}-\mathrm{Mg}$ TIG welding joints [5]. One of the reasons for the variance on intermetallic compounds in the above studies may lie on the different heat input in welding experiments. FSW and USW are solid stated welding methods, thus, they have lower heat input than TIG welding laser-TIG and CMT. 


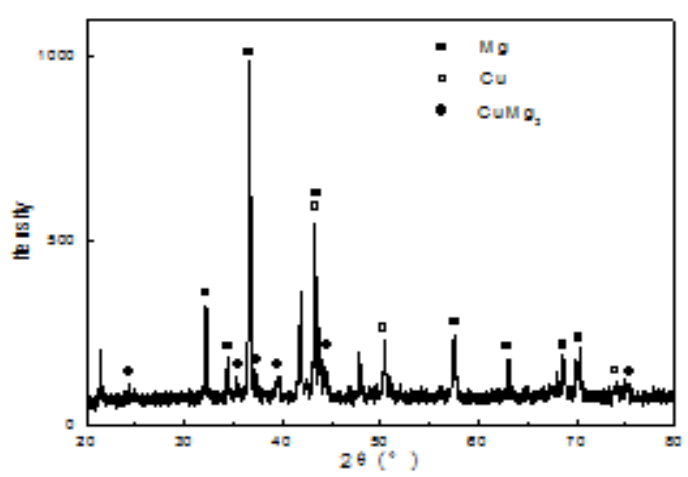

Fig. 7 X-ray diffraction pattern.

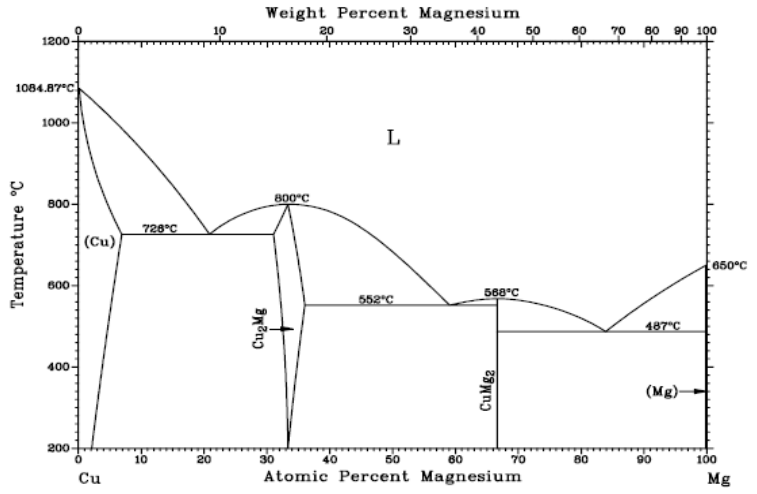

Fig. $8 \mathrm{Cu}-\mathrm{Mg}$ binary phase diagram.

Mechanical Properties of Dissimilar Joint. Fig. 9(a) and (b) show the macrograph of tensile specimens before and after tensile testing, and the location of the fracture can be seen clearly in Fig. 9(b). All three samples fractured at the interface between $\mathrm{Cu}$ and $\mathrm{Mg}$ of the joints. The tensile strength of the $\mathrm{Mg}-\mathrm{Cu}$ dissimilar joints are relatively low, with an ultimate tensile strength (UTS) of $86 \mathrm{MPa}$, which is only $34.5 \%$ of the $\mathrm{Mg}$ base metal.
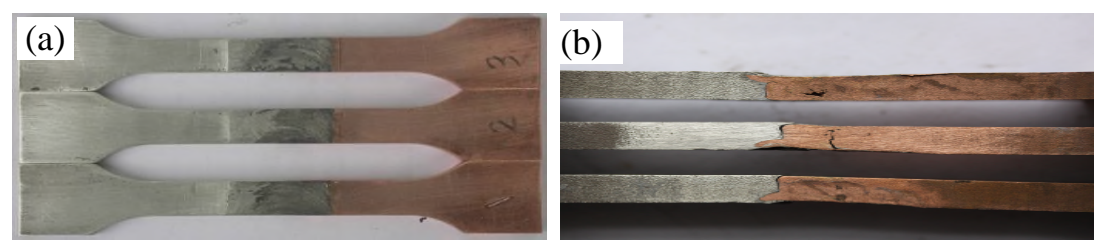

Fig. 9 Macrographs of tensile samples (a) before tensile test (b) after tensile test.

Fig. 10 shows the fracture surface for $\mathrm{Mg}$ side of $\mathrm{Mg}-\mathrm{Cu}$ dissimilar joint.
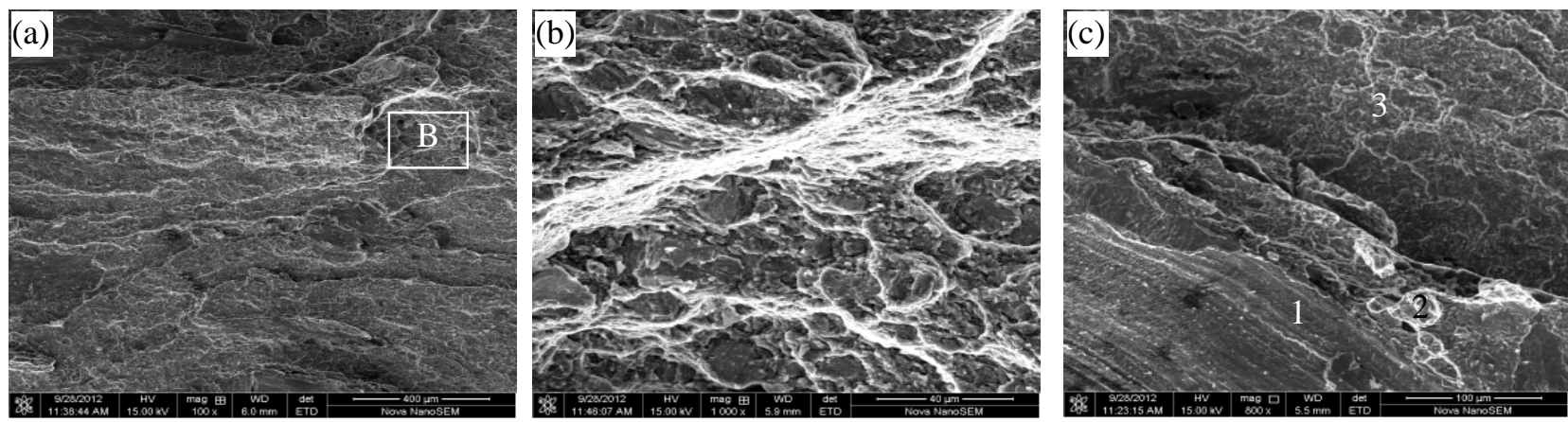

Fig. 10 SEM images of tensile fracture surface:(a) graph of tensile fracture surface; (b) Magnified of regions marked B in Fig. 10(a); (c) EDS test area; (d) river patterns shown in the fracture surface.

As shown in Fig. 10(a), cleavage step and tearing ridge are found at the fractured surface indicating a brittle fracture mode of the joint. Furthermore, river patterns and flat surface presented in Fig. 10(c) also certificated the joints brittle fracture mode. The EDS test taken from point 1 to 3 marked in Fig. 10(c) results are listed in the Table 2. The elements concentration presented in Table 2 shows a possible phase of $\alpha-\mathrm{Mg}+\mathrm{CuMg}_{2}$. These results are probably caused by the presence of newly formed intermetallic compounds as presented by the XRD results shown in Fig. 8 and the EDS test results shown in Table 2, respectively. However, dimples shown in Fig. 10(b) with small amount and size suggested that the dissimilar materials joint has low plastic. 
Table 2. The EDS test results of areas marked 1-3 in Fig. 10(c).

\begin{tabular}{cccc}
\hline Elements & Area 1 & Area 2 & Area 3 \\
\hline $\mathrm{Mg}$ & 68.95 & 77.43 & 72.26 \\
$\mathrm{Al}$ & 3.13 & 1.25 & 2.04 \\
$\mathrm{Cu}$ & 27.92 & 21.32 & 25.70 \\
Possible phases & \multicolumn{3}{c}{$\alpha-\mathrm{Mg}+\mathrm{Mg}_{2} \mathrm{Cu}$} \\
\hline
\end{tabular}

\section{Summary}

Pure copper and AZ31 magnesium alloy are jointed successfully through FSW with pin offset technique under a tool rotation rate of $1180 \mathrm{r} / \mathrm{min}$ and a traverse speed of $38 \mathrm{~mm} / \mathrm{min}$. Compared with the base materials, both copper and magnesium are greatly refined after FSW. $\mathrm{CuMg}_{2}$ intermetallic compounds were found in the nugget zone. The hardness of the stir zone was much higher than that of the base material. The maximum value of hardness existing in the middle of the stirred zone. The UTS of the joint was $86 \mathrm{MPa}$ and the joint failed with a brittle fracture mode.

\section{Acknowledgments}

The work was supported by the fund of National Natural Science Foundation of China (No. 51265042) and Jiangxi Natural Science Foundation (No. 20114BAB206006).

\section{Reference}

[1] T. M. Pollock, Weight loss with magnesium alloys, Sci.. 328 (2010) 986-987.

[2] W. M. Elthalabawy, T. I. Khan, Eutectic bonding of austenitic stainless steel 316L to magnesium alloy AZ31 using copper interlayer, Int. J. Adv. Manuf. Technol. 55 (2011) 235-241.

[3] J. R. Davis. Copper and Copper Alloys, ASM International, 2001.

[4] G. Mahendran, V. Balasub Ramanian, T. Senthilvelan. Developing diffusion bonding windows for joining AZ31B magnesium and copper alloys, Int. J. Adv. Manuf. Technol. 42(2009) 689-695.

[5] L. M. Liu, S. X. Wang, L. M. Zhao, Study on the dissimilar magnesium alloy and copper lap joint by TIG welding, Mater. Sci. Eng. A . 476 (2008) 206-209.

[6] C. W. Tan, W. X. He, X. T. Gong, Influence of laser power on microstructure and mechanical properties of fiber laser-tungsten inert gas hybrid welded $\mathrm{Mg} / \mathrm{Cu}$ dissimilar joints, Mater. Des. 78 (2015) 51-62.

[7] R. Cao, M. Jing, Z. Feng, J. H. Chen, Cold metal transfer welding-brazing of magnesium to pure copper, Sci. Technol. Weld Joi. 19 (2014) 451-460.

[8] G. Mahendran, V. Balasub Ramanian, T. Senthilvelan, Influences of diffusion bonding process parameters on bond characteristics of $\mathrm{Mg}-\mathrm{Cu}$ dissimilar joints, Trans. Nonferrous Met. Soc. China. 20 (2010) 997-1005.

[9] R. S. Mishra, Z. Y. Ma, Friction stir welding and processing, Mater. Sci. Eng. R. 50 (2005) $1-78$. 